\title{
Headaches among Operation Iraqi Freedom/Operation Enduring Freedom veterans with mild traumatic brain injury associated with exposures to explosions
}

\author{
Robert L. Ruff, MD, PhD; ${ }^{1-2 *}$ Suzanne S. Ruff, PhD; ${ }^{3}$ Xiao-Feng Wang, $\mathbf{P h D}^{\mathbf{4}}$ \\ ${ }^{1}$ Neurology Service and Polytrauma System of Care, Louis Stokes Cleveland Department of Veterans Affairs Medical \\ Center (VAMC), Cleveland, $\mathrm{OH} ;{ }^{2}$ Department of Neurology, Case Western Reserve University, Cleveland, $\mathrm{OH}$; \\ ${ }^{3}$ Psychology Service and Polytrauma System of Care, Louis Stokes Cleveland VAMC, Cleveland, OH; ${ }^{4}$ Department of \\ Quantitative Health Sciences, The Cleveland Clinic, Cleveland, $\mathrm{OH}$
}

\begin{abstract}
Traumatic brain injury (TBI) is a common injury type among Operation Iraqi Freedom/Operation Enduring Freedom (OIF/OEF) veterans, and headaches are a frequent consequence of TBI. We examined the hypothesis that among veterans who reported mild TBI caused by exposure to an explosion during deployment in OIF/OEF, those with residual neurocognitive deficits would have a higher frequency of headaches and more severe headaches. We evaluated 155 consecutive veterans with neurological examination and neuropsychological testing. We excluded 29 veterans because they did not have mild TBI or they did not complete the evaluation. We analyzed headache pattern, intensity, and frequency. Among the 126 veterans studied, 80 had impairments on neurological examination or neuropsychological testing that were best attributed to TBI. Veterans with impairments had been exposed to more explosions and were more likely to have headache, features of migraine, more severe pain, more frequent headaches, posttraumatic stress disorder, and impaired sleep with nightmares.
\end{abstract}

Key words: blast, combat, explosion, headache, migraine, OEF, OIF, pain, sleep, traumatic brain injury.

\section{INTRODUCTION}

Traumatic brain injury (TBI) is an important health issue in both military and civilian life [1-3]. TBI resulting from exposure to explosions is highly prevalent among military personnel who served in Operation Iraqi Freedom/Operation Enduring Freedom (OIF/OEF) [3]. Mild TBI may also be referred to as concussion. Headache, a frequent sequel to head trauma [4-5], usually resolves within 6 months for civilians with mild TBI [5]. Headache patterns have been reported among military personnel, but these reports focused on individuals with moderate or severe TBI [6-7]. The usual patterns for headaches are tension-like, migraine-like, and mixed tension/migraine [7]. Among veterans with moderate or

Abbreviations: $\mathrm{CI}=$ confidence interval; CVLT-II $=$ California Verbal Learning Test, Second Edition; LSCVAMC = Louis Stokes Cleveland Department of Veterans Affairs Medical Center; MMPI-II = Minnesota Multiphasic Personality Inventory, Second Edition; MRI = magnetic resonance imaging; OIF/ $\mathrm{OEF}=$ Operation Iraqi Freedom/Operation Enduring Freedom; $\mathrm{OR}=$ odds ratio; $\mathrm{PTSD}=$ posttraumatic stress disorder; $\mathrm{SE}=$ standard error of the mean; TBI = traumatic brain injury; VA = Department of Veterans Affairs; VHA = Veterans Health Administration; WAIS-III = Wechsler Adult Intelligence Scale, Third Edition; WMS-III = Wechsler Memory Scale, Third Edition.

* Address all correspondence to Robert L. Ruff, MD, PhD; Neurology Service 127(W), Louis Stokes Cleveland VAMC, 10701 East Blvd, Cleveland, OH 44106; 215-791-3800, ext 5230; fax: 216-707-5934. Email: Robert.Ruff1@va.gov DOI: 10.1682/JRRD.2008.02.0028 
severe TBI treated in the four Veterans Health Administration (VHA) Polytrauma Centers, the prevalence of headaches at the onset of treatment was 38 percent [6]. Most individuals had frequent or daily headaches. Headaches resolved in about half the veterans after 6 months, but those with headaches after 6 months also continued to have headaches after 1 year. The most frequent pattern of TBI among OIF/OEF veterans is mild TBI [2-3]; however, a paucity of information exists about headaches in veterans with mild TBI.

The veterans were categorized based on whether they had persistent residuals of TBI as determined by neurological examination and neuropsychological testing. The primary hypothesis of this article is that veterans with residual neurocognitive deficits after TBI will be more likely to have headaches. The secondary hypotheses related to veterans with residual neurocognitive deficits is that they will have (1) more severe headache pain, (2) different headache characteristics, (3) higher prevalence of posttraumatic stress disorder (PTSD) and impaired sleep, (4) been exposed to more explosions, and (5) more recently been exposed to an explosion.

\section{METHODS}

This study was a Quality Assurance Monitor of the evaluation of OIF/OEF veterans. All veterans were evaluated in the Louis Stokes Cleveland Department of Veterans Affairs (VA) Medical Center (LSCVAMC) in Cleveland, Ohio, which is a second-level VHA Polytrauma Center.

The study was approved and continuously reviewed by the Quality Assurance Committee of the Neurology and Quality Assurance Services, the Medical Executive Committee, and the institutional review board of the LSCVAMC.

\section{Primary and Secondary TBI Screening}

We evaluated 155 OIF/OEF veterans who were identified by the VHA TBI screening tool [8]. The screening tool is administered to all OIF/OEF veterans treated by VHA. For those who confirm OIF/OEF deployment and do not have a prior diagnosis of TBI, the instrument proceeds with four sequential sets of questions. If the patient responds negatively to any of the sets of questions, the screen is negative. If the patient responds positively to one or more possible answers in each of the four sections, the screen is positive. The four sections are (1) events that may increase the risk of TBI, such as exposure to an explosion; (2) immediate symptoms following the event including loss or altered consciousness or posttraumatic amnesia; (3) new or worsening symptoms following the event; and (4) current symptoms that are consistent with TBI. The symptoms in the screen included alterations in cognition, behavior, motor or sensory function, and balance or coordination and the presence of pain including headache. Not all patients whose screens are positive have TBI. A patient may respond positively to all four sections because of the presence of other conditions, such as PTSD without TBI, cervicocranial injury with headaches, or inner ear injury. Therefore, patients are not labeled with the diagnosis of TBI on the basis of a positive screening test. They undergo a second-level evaluation including a neurological examination, neuropsychological testing, and evaluation of the neuropsychological tests by a certified neuropsychologist. From the group of 155 veterans, we excluded 29 from consideration in this article for the following reasons: (1) the initial screen was not truly positive because a veteran did not understand a question (4 veterans), (2) the veteran had moderate or severe TBI or had sustained penetrating TBI (8 veterans), (3) TBI was not due to exposure to an explosion (6 veterans), and (4) the veteran did not complete the second-level evaluation (11 veterans).

The remaining 126 veterans who had a positive initial TBI screen had historical evidence of mild TBI based on the duration of loss of consciousness or alteration of consciousness. These veterans did not have a penetrating head injury. The criteria for mild TBI were that for each episode of TBI the duration of loss of consciousness was less than 30 minutes, the duration of any alteration in mental state (e.g., confusion, disorientation, slowed thinking) following the TBI was less than 24 hours, and the period of any posttraumatic amnesia was less than 24 hours. These criteria are consistent with existing criteria for mild TBI [1,9-12]. These 126 veterans were separated into two groups according to whether a veteran had evidence of brain dysfunction based on neurological examination, neuropsychological testing, or both.

\section{Neurological Examination}

The neurological examination included a brief screen of cognition and evaluation of cranial nerve, motor, sensory, coordination, reflex, gait, and balance functions [13]. The Montreal Cognitive Assessment Test was the 
cognitive function screen. Montreal Cognitive Assessment Test scores of 26 or higher were considered normal [14-15]. Cranial nerve evaluation included evaluation of olfactory function, direct funduscopic examination, confrontation visual field testing, pupil size and light reactivity, horizontal and vertical smooth pursuit eye movements, facial sensation to sharp and light touch sensations, masseter muscle bulk and strength, hearing assessment with a $512 \mathrm{~Hz}$ tuning fork, gag reflex and palate movement, sternomastoid muscle mass and strength, and symmetry of tongue protrusion. Olfaction was tested with a 12-item "scratch-and-sniff" testing instrument, called the Brief Smell Identification Test (Sensonics, Haddon Heights, New Jersey; http://www.sensonics.com) [16]. The olfactory testing instrument has normal performance values that are adjusted for age and sex [17-18]. Olfactory testing using this scratch-and-sniff type of testing instrument has been validated for all severities of TBI [19-23]. Motor testing evaluated muscle tone, muscle power testing, upper-limb drift, and the arm-rolling maneuver [24]. Sensory testing included evaluation of pin, light touch, and proprioception in the fingers and toes, and also evaluation of extinction on double simultaneous stimulation, topagnosia, and somatotopagnosia. Coordination testing included evaluation of rapid alternating movements in the upper limbs, foot tapping, finger-to-nose testing, and heel-to-shin testing. The Romberg test assessed balance [25]. The neurologist was not aware of the findings of neuropsychological testing when he performed the neurological examination. Abnormalities discovered on the neurological examination were interpreted to consider whether they were best explained by injury to the brain or to the other parts of the nervous systems. When no history of impaired olfaction predated OIF/OEF deployment, olfactory impairment was attributed to TBI. Impaired ocular motor function was attributed to TBI, except in one individual whose pattern of fine continuous nystagmus was present from infancy and best explained by congenital nystagmus.

\section{Characterization of Headaches}

Each veteran was queried about the presence of headaches. If the veteran experienced headaches, we determined whether the headaches were associated with OIF/ OEF deployment. If the veteran had deployment-associated headaches, we recorded the pattern, character, frequency, and severity of the headaches. The highest pain level that a patient experienced during a headache was scored on a numerical rating scale from 0 to 10 , with 0 being no pain and 10 being unbearable pain [26]. In association with inquiring about headaches, veterans were also queried as to whether they had impaired sleep and the nature of the sleep impairment. Veterans were specifically questioned about the presence of nightmares.

The International Headache Society classification for headaches includes a distinct category for posttraumatic headaches [4]. The three usual patterns of headache associated with TBI are muscle tension, migraine, or mixed tension/migraine [7]. We characterized each subject's headaches as tension-like, migraine-like, or mixed tension/migraine based on whether the characteristics of the headaches fit the International Headache Society criteria for tension headaches or migraine headaches or had features of both headache types [4]. Tension headaches have at least two of the following four criteria: (1) bilateral pain, (2) pain that is pressing or tightening but not pulsating, (3) mild to moderate intensity, or (4) not aggravated by physical activity. Tension headaches are not accompanied by nausea or vomiting. Tension headaches may be accompanied by phonophobia or photophobia, but not both. During a tension headache, patients may have tenderness of pericranial muscles, including the temporalis, masseter, pterygoid, sternocleidomastoid, splenius, or trapezius muscles. Most individuals who develop posttraumatic migraine headaches have headaches that resemble migraine without aura, which is also called common migraine. The criteria for common migraine are recurrent episodes of pain lasting for 4 to 72 hours with at least two of the following four characteristics: (1) unilateral, (2) pulsating quality, (3) moderate or severe intensity, or (4) aggravated by or causing avoidance of routine physical activity. In addition, migraines have at least one of the following two characteristics: (1) nausea, vomiting, or both and (2) phono- or photophobia or both. Among individuals who experienced migraine headaches prior to head trauma, posttraumatic migraine headaches are associated with a definite increase in headache frequency or intensity or change in the pain pattern following head trauma. Mixed tension/migraine headaches have features of both headache types; for example, severe bilateral nonthrobbing pain associated with nausea or accompanied with both photo- and phonophobia. Veterans who had two types of headaches, both migraine-like and tension-like, were categorized as having mixed headaches. 


\section{Neuropsychological Assessment}

Each veteran was evaluated by one of two certified neuropsychologists at the LSCVAMC. Neuropsychological testing was individualized for each subject; however, each subject received a minimum battery of neuropsychological tests to assess the following areas: (1) intelligence; (2) executive functioning, including attention and tracking; short-term and working memory; and initiating, sustaining, and retrieving information; (3) language; (4) planning and problem solving; (5) visuospatial memory; (6) secondary memory and learning; (7) tests of effort to assess for malingering; (8) depression; (9) anxiety; and (10) personality and symptom validation with the use of the second edition of the Minnesota Multiphasic Personality Inventory (MMPI-II) [27]. A neuropsychologist interpreted the test results and determined if the findings were most consistent with TBI or whether abnormal findings were better explained by another process such as PTSD. Intelligence was assessed with the fourth edition of the Wide Range Achievement Test [28] and the information subtest of the third edition of the Wechsler Adult Intelligence Scale (WAIS-III) [29]. Attention and information tracking were assessed with the Stroop Color Name and Color Word Tests [30-31] and the Paced Auditory Serial Addition Test [32-33]. Short-term and working memory were evaluated with the Auditory Consonant Trigram Test [34], the letter-number sequencing subtest of the WAIS-III, and the Trail Making Test parts A and B [35-37]. The ability to initiate, sustain, and retrieve information was measured with the Controlled Oral Word Association Test (also called the F-A-S test) and animal naming [38-40]. Language function was examined with the Boston Naming Test $[35,41]$. Planning, problem solving, and cognitive flexibility were evaluated with the Porteus Maze Test [4243] and the full version of the Wisconsin Card Sort Test [44-45]. Visual spatial memory was measured with the Rey Complex Figure Test [46-48]. Secondary memory and learning ability were evaluated with the third edition of the Wechsler Memory Scale (WMS-III) [49-53], the full version of the second edition of the California Verbal Learning Test (CVLT-II) [54-56], and the Rey Complex Figure Test. The likelihood that the responses given on neuropsychological testing were sincere and that the subjects were applying a good effort was assessed by interpretation of performance on several tests, including the Test of Memory Malingering [57-58], the WMS-III [52-53], and the MMPI-II [59]. Depression was assessed with the sec- ond edition of the Beck Depression Inventory [60]. Anxiety was assessed with the Beck Anxiety Inventory [61].

We evaluated each veteran's performance on neuropsychological testing to consider whether the findings were valid and whether they were consistent with neurocognitive sequelae of TBI or better explained by another process. The features of cognitive function considered most likely to be disturbed by TBI included working memory; attention (including focusing of attention in the presence of distraction); speed of processing; secondary verbal and visuospatial memory; and executive functions such as planning, organization, and nonroutine problem solving. In determining whether the neuropsychological testing results indicated residual neurocognitive sequelae of TBI, the neuropsychologists focused on performance in six areas of performance: (1) executive functioning, (2) visuospatial functioning, (3) attention, (4) working memory, (5) speed of processing, and (6) secondary verbal and visuospatial memory. For an individual to be considered to have persisting neurocognitive sequelae of TBI, that individual needed to show impairments in two or more of the six targeted areas of neurocognitive functioning, those deficits could not be better attributed to another cause, and the neuropsychologist needed to believe that the neuropsychological test results accurately reflected the individual's performance ability.

\section{PTSD}

Every veteran undergoes a screen for PTSD when he or she enters VA care. The initial screen consists of four questions, introduced with, "In your life, have you ever had any experience that was so frightening, horrible, or upsetting that, in the past month, you experienced any of the following: (1) Have had nightmares about it or thought about it when you did not want to? (2) Tried hard not to think about it or went out of your way to avoid situations that reminded you of it? (3) Were constantly on guard, watchful, or easily startled? (4) Felt numb or detached from others, activities, or your surroundings?” If a veteran acknowledges any three items, the screen is considered positive and the veteran is referred for further evaluation by a mental health professional who is trained and qualified to recognize and diagnose PTSD. The PTSD evaluation includes a 17-item National Center for PTSD Checklist for symptoms of PTSD [62]. The PTSD Checklist is based on well-validated case definitions used in veteran and military populations [63-65]. Each item has five possible responses with scoring values of 1 to 5 , 
with 1 point being "not at all" and 5 points being "extremely." Thus, the total range for the PTSD Checklist is 17 to 85 points. For a diagnosis of PTSD, a subject has to satisfy the criteria of the American Psychiatric Association's Diagnostic and Statistical Manual of Mental Disorders, Fourth Edition, which requires at least one intrusion symptom, three avoidance symptoms, and two hyperarousal symptoms [66]. In addition, the individual has to have substantial distress, as measured by a total score of at least 50 on the PTSD Checklist.

\section{Statistical Methods}

The independent variables were (1) interval in months from last blast exposure associated with loss of consciousness, alteration in consciousness, or posttraumatic amnesia; (2) number of historical blast exposures associated with lost or altered level of consciousness; (3) presence of PTSD; presence of abnormalities on elements of the neurological examination including (4) olfaction, (5) eye movements, (6) motor examination, (7) sensory examination, (8) balance, (9) coordination, (10) gait, and (11) reflex evaluation; (12) presence of abnormalities on neuropsychological testing that were most consistent with TBI and not better explained by another process; and (13) presence of disturbed sleep. The dependent variables were (1) presence of TBI indicated by abnormalities on neurological examination, neuropsychological testing, or both; (2) presence of headaches; (3) headache pattern as tension-like, migraine-like, or mixed; (4) number of headaches per month; and (5) severity of headache pain. The relationship between the presence of TBI and the independent variables was determined with an association analysis that used the chi-square goodness-of-fit test [67]. The Appendix (available online only at http:// www.rehab.research.va.gov/jour/08/45/7/pdf/contents.pdf/) contains a table with the results of an association analysis for the presence of neurocognitive deficits with independent variables using the chi-square goodness-of-fit test. Where applicable, we used an odds ratio (OR) and a 95 percent confidence interval (CI) to compare results. The relationships of the number and severity of headaches with impaired sleep and PTSD were evaluated with logistic regression analysis [68]. We used the Pearson Correlation test to examine the relationships among headache severity, the number of blast exposures and the interval since the last blast exposure [69]. We used the Bonferroni method to correct for multiple comparisons [70-71]. Values are presented as means \pm standard error of the mean (SE).

\section{RESULTS}

For the 126 veterans with a reported history of mild TBI, we evaluated the findings on neurological examination and neuropsychological testing to determine whether abnormal findings were best attributed to TBI or to another process. To evaluate the primary hypothesis that veterans with neurocognitive deficits would have a higher prevalence of headaches, we divided the subjects based on whether they had deficits identified on neurological examination or neuropsychological testing and found 80 veterans with evidence of brain dysfunction that was best explained by TBI (Table 1). We found 59 veterans (74\%) with abnormal neurological and neuropsychological assessments and only 6 veterans (7.5\%) with an abnormality on neurological examination and no deficits on neuropsychological testing that were best attributed to TBI. Just 3 veterans (4\%) had impaired olfaction as their only abnormality. Fifteen veterans (19\%) had abnormalities on neuropsychological testing and normal neurological examinations. The most sensitive test on the neurological examination was olfaction. The number of veterans with abnormalities on different parts of the neurological examination were olfaction $=65$, balance $=14$, eye movements $=$ 13 , motor $=2$, and sensory $=2$. Among the 65 veterans with abnormalities on neurological examination, 41 (63\%) had only impaired olfaction. Abnormal neuropsychological testing and impaired olfaction had the strongest associations with residual neurocognitive deficits (each $p<$ 0.001).

The primary hypothesis that veterans with neurocognitive deficits would have a higher prevalence of headaches was supported by the data. Of all the veterans with cerebral dysfunction, 93 percent had headaches, compared with 13 percent of veterans without cerebral impairment (Table 2, $p<0.001$, OR $=82.2$ with 95\% CI of 24.9271.7). In addition, the secondary hypotheses that veterans with residual neurocognitive deficits would have different headache characteristics and more severe pain were also supported by the data. Veterans with persisting

Table 1.

Frequency of abnormalities on neurological and neuropsychological testing among 80 veterans with mild traumatic brain injury.

\begin{tabular}{lcc}
\hline \multirow{2}{*}{ Neurological Testing } & \multicolumn{2}{c}{ Neuropsychological Testing } \\
\cline { 2 - 3 } & Abnormal & Normal \\
\hline Abnormal & 59 & 6 \\
Normal & 15 & 0 \\
\hline \hline
\end{tabular}


neurocognitive deficits were more likely to have headaches with migraine features. All the veterans without cerebral impairment had tension-like headaches, whereas 60 percent of the veterans with cerebral impairment had migraine-like or mixed headaches (Table 2, $p<0.001$ ). Of the 44 individuals who had headaches with migraine features, 8 had a history of childhood migraine that did not persist into adulthood. None had active migraine at the onset of their OIF/OEF deployments. Veterans with persisting cerebral impairment had more frequent headaches (Table 3, $p<$ $0.001)$. The mean number of headaches per month was $12.4 \pm 0.94$ for veterans with persisting cerebral injury, compared with $4.50 \pm 0.34$ for veterans without persisting cerebral dysfunction $(p<0.001)$. The peak pain level during headaches was greater for veterans with persisting cerebral dysfunction (Table 3).

Two of the secondary hypotheses related to veterans with residual neurocognitive deficits were that they would (1) have been exposed to more explosions and (2) have more recently been exposed to an explosion. The presence of residual neurocognitive deficits was associated with exposure to a larger number of explosions, but not associated with the elapsed time since the last blast exposure. Only one veteran reported a brief episode of altered consciousness lasting less than 1 minute prior to entry into military service. He reported that the episode occurred in a high school sporting event. That veteran did not have residual neurocognitive deficits. No veteran reported suffering a concussion after deployment in OIF/OEF. The mean number of blast exposures associated with loss or alteration of consciousness was $4.42 \pm 0.23$ for veterans with evidence of residual brain damage, compared with $2.65 \pm 0.18$ for veterans with no persisting signs of brain injury $(p<$ 0.001). Each veteran reported at least one episode of loss of consciousness due to an explosion. The mean number of blast exposures associated with loss of consciousness was $3.91 \pm 0.20$ for veterans with evidence of residual brain damage compared with $1.46 \pm 0.09$ for veterans with no persisting signs of brain injury $(p<0.001)$. Among the veterans with residual neurocognitive deficits, 91 percent reported multiple episodes of loss of consciousness compared with 39 percent of the veterans who did not have deficits $(p<0.001$, OR $=16.2$ with 95\% CI of 6.11-43.0). The interval from the last blast exposure to the evaluation was similar for the 80 veterans who had evidence of persisting neurological or cognitive deficits and the 46 veterans who did not. The interval range was 8 months to 4.5 years. The median/mean intervals in months were $30.5 / 30.8$ for veterans with deficits and 29.5/30.5 for veterans without deficits.

The data supported the secondary hypotheses that veterans with residual neurocognitive deficits will have higher prevalence of PTSD and impaired sleep (Table 4). The frequency of PTSD was 90 percent for veterans with neurocognitive deficits compared with 24 percent for veterans without neurocognitive deficits $(p<0.001$, OR $=$ 28.6 with 95\% CI of 10.6-77.6). The frequency of impaired sleep was 83 percent for veterans with neurocognitive deficits, compared with 11 percent for veterans without neurocognitive deficits $(p<0.001$, $\mathrm{OR}=38.7$ with 95\% CI of 13.0-115.3). The most common sleep impairment was agitated sleep with nocturnal awakenings due to

Table 2.

Character of headaches associated with blast exposure.

\begin{tabular}{|c|c|c|c|}
\hline \multirow{2}{*}{ Patient Group (No. with Headaches/Total No.) } & \multicolumn{3}{|c|}{ Headache Type, No. (\%) } \\
\hline & Tension & Migraine & Mixed \\
\hline Neurocognitive Deficit (74/80) & $30(41)$ & $14(19)$ & $30(41)$ \\
\hline
\end{tabular}

Table 3.

Headache frequency and severity.

\begin{tabular}{lccc}
\hline \multicolumn{1}{c}{ Patient Group (No. with Headaches) } & $\begin{array}{c}\text { Peak Pain Intensity* } \\
\text { (Mean } \pm \text { SE) }\end{array}$ & \multicolumn{2}{c}{ Frequency, No. (\%) } \\
\cline { 3 - 4 } & >4/Month & $>$ 10/Month & Daily \\
\hline Persisting Deficit (74) & $7.28 \pm 0.27 \dagger$ & $71(96) \dagger$ & $31(42)$ \\
Negative Neurological \& Neuropsychological Testing (6) & $4.33 \pm 0.27$ & $2(33)$ & 0 \\
\hline${ }^{*}$ Rated on 0-10 scale. & & \\
${ }^{\dagger} p<0.001$. & & \\
SE $=$ standard error of the mean. & & \\
\hline \hline
\end{tabular}


Table 4.

Presence of posttraumatic stress disorder (PTSD) and impaired sleep among veterans with and without persisting brain dysfunction.

\begin{tabular}{lcc}
\hline \multicolumn{1}{c}{ Patient Group (No.) } & PTSD, No. (\%) & Disturbed Sleep, No. (\%) \\
\hline Persisting Deficit (80) & $72 / 80(90)$ & $66 / 80(82.5)$, All with PTSD \\
Negative Neurological \& Neuropsychological Testing (46) & $11 / 46(24)^{*}$ & $5 / 46(11)^{*}$ \\
\hline${ }^{*} p<0.001$. & & \\
\hline
\end{tabular}

nightmares. Among the veterans with impaired sleep, all those with cerebral dysfunction had awakenings due to nightmares. In contrast, only one of those without cerebral dysfunction had nightmares. Impaired sleep was strongly associated with PTSD for veterans with persisting cerebral impairments but only slightly associated for veterans without cerebral dysfunction. All the veterans with neurocognitive deficits who had impaired sleep also had PTSD and 94 percent of those with PTSD had impaired sleep. In contrast, among the veterans who did not have a neurocognitive deficit, only 1 of 11 veterans (9\%) with PTSD had impaired sleep.

We used logistical regression analysis to further investigate the relationships between impaired sleep and PTSD with headache severity and the frequency of headaches. Strong associations existed for veterans with persisting neurocognitive deficit, but no associations for veterans without cerebral dysfunction. Among veterans with neurocognitive deficit, the presence of impaired sleep was associated with higher levels of pain (Wald $\chi^{2}=$ $12.0, p<0.001$ ) and more frequent headaches (Wald $\chi^{2}=$ $11.8, p<0.001)$. Strong associations also existed between the presence of PTSD and the headache frequency (Wald $\left.\chi^{2}=12.2, p<0.001\right)$ and between PTSD and the intensity of headache pain (Wald $\chi^{2}=13.9, p<0.001$ ). Neither of the two groups of veterans had associations between headache frequency or intensity and either the number of blast exposures or the duration of time from the last blast exposure.

\section{DISCUSSION}

The data supported the primary hypothesis that veterans with residual neurocognitive deficits after TBI would be more likely to have headaches (Table 2). The data also supported most of the secondary hypotheses. Veterans with residual neurocognitive deficits had more intense headache pain and were more likely to have headaches that had features of migraine (Table 2). Their headaches were more severe and occurred more frequently (Table 3). They also had a higher prevalence of PTSD and impaired sleep (Table 4). In addition, the veterans with neurocognitive impairments reported being exposed to more explosions that produced loss or alteration of consciousness. The secondary hypothesis that was not supported was that veterans with neurocognitive deficits had been more recently been exposed to an explosion. No difference existed in the interval since the last blast exposure for veterans who did and did not have neurocognitive deficits.

Several potential biases may have influenced the findings. First, this was not a random sample of soldiers who sustained mild TBI during deployment in OIF/OEF. Not all veterans seek care within VHA after OIF/OEF deployment. Veterans who are having issues with pain or behavioral changes may be more likely to seek VHA care. Second, the initial screening process used to identify veterans who had a history of TBI required a veteran to report having active symptoms that could be associated with TBI. Veterans who had actually experienced a concussion but whose symptoms resolved would not have been identified by the initial screen. Third, the history indicating TBI was based on self-report of a remote event. This problem is inherent in dealing with a nonlife-threatening event in a combat environment. Veterans could possibly underestimate the duration of changed consciousness, and some of those that we felt had mild TBI may have had more severe TBI. We did not rely on neuroimaging in diagnosing mild TBI, because imaging is not routinely indicated for mild TBI. However, 52 individuals did have magnetic resonance imaging (MRI) or computer tomography brain imaging studies, all of which were interpreted as normal. In contrast, each of the eight veterans who were excluded from this study because their histories indicated moderate TBI had neuroimaging, and five had abnormalities on neuroimaging studies. Of note, individuals with mild TBI may have normal-appearing conventional MRI studies and still manifest abnormalities on studies of regional cerebral blood flow [72] or diffusion-tensor MRI [73].

We depended on the clinical impression of neuropsychologists interpreting the neuropsychological test battery 
in determining whether deficits were best attributed to TBI or to another condition, such as PTSD. The neuropsychological tests we used have been used to characterize neurocognitive changes associated with TBI, including the fourth edition of the Wide Range Achievement Test [29], the Stroop Color Name and Color Word Tests [30-31], the Paced Auditory Serial Addition Test [32-33], the Auditory Consonant Trigram Test [35,74], the Trail Making Test parts A and B [35-37], the Controlled Oral Word Association Test and animal naming [38-40], the Boston Naming Test [35,41] the Porteus Maze Test [42-43], the Wisconsin Card Sort Test [45], the Rey Complex Figure Test [46-47], the WAIS-III and WMS-III [5053], the CVLT-II [55-56], the Test of Memory Malingering [57-58], the WMS-III [52], and the MMPI-II [59]. While the pattern of findings on neuropsychological testing may suggest TBI, neuropsychological testing is not diagnostic. Hence, the use of neuropsychological testing does not provide a certain diagnosis of TBI.

In this study, the most sensitive tool for detecting residual brain dysfunction on neurological examination was olfactory testing. In studies of TBI resulting from noncombat trauma, approximately 60 percent of individuals with moderate to severe TBI have impaired olfaction [20,22,75]. In this report, 52 percent of the 126 veterans with a history of mild TBI had impaired olfaction. Head injury usually impairs olfaction by shearing the olfactory nerves at the cribriform plate. Bruising of the antero-medial aspect of the frontal lobes, the center for olfaction, can also compromise olfaction [76]. MRI studies of civilians with posttraumatic anosmia demonstrated damage to the olfactory bulbs and tracts, subfrontal cortex, and temporal lobes [77-78]. Importantly, individuals often do not recognize that they have impaired olfaction following TBI [75]. An unrecognized environmental exposure may have increased the number of individuals with olfactory impairments or increased the likelihood that concussion would cause impaired olfaction. We are not aware of other studies of olfactory function among veterans deployed in OIF/OEF.

Mild TBI can produce subtle impairments in neurological functions other than olfaction. In civilians with head-trauma, impaired balance is acutely present in about 40 percent of individuals [79-80] and about 40 percent have impaired eye movements [56,81]. However, the detailed evaluation of balance and eye movement function that is needed to detect the subtle changes produced by mild TBI requires sophisticated testing equipment. Hence, these assessments need to be done in special laboratory settings. At this time, olfactory testing is the most sensitive bedside indicator of persisting brain injury. Another reason that olfaction is a good test for remote TBI is that olfaction usually does not recover after TBI [23].

In this study, the veterans who had persisting neurocognitive deficits reported being exposed to more explosions that produced changes in consciousness. This observation is consistent with animal studies that suggest that repeated episodes of head trauma will increase the likelihood of cerebral injury [82-83].

In this report, 63 percent of the 126 veterans studied had headaches. The frequency was higher, 92 percent, among the veterans with persisting neurocognitive impairments and lower, 13 percent, among those without neurocognitive deficits. In civilian populations, between 22 and 95 percent of individuals with TBI report chronic pain, usually headache [84]. Chronic headaches appear to be common in those with mild TBI. Approximately 30 to 90 percent of individuals with mild TBI have posttraumatic headaches compared with 33 percent of those with moderate to severe TBI [84]. Unfortunately, a high incidence of TBI exists among personnel deployed in OIF/OEF. Among those who have experience traumatic combatrelated polytraumatic injuries, including TBI, the point prevalence estimates of pain are between 65 and 97 percent [85].

The 80 veterans with neurocognitive deficits were more likely to have PTSD and impaired sleep. In addition, both PTSD and sleep were associated with headache frequency and intensity. Among the veterans with neurocognitive deficits, PTSD and impaired sleep were strongly associated. Other studies have noted an association between combat-acquired TBI and PTSD in military personnel deployed in OIF/OEF [65]. Hoge et al. found that soldiers who were deployed to Iraq and who reported histories of loss of consciousness were more likely to meet criteria for PTSD and to report poor health; however, after adjustment for PTSD and depression, mild TBI was no longer associated with poor health except for headache [65]. Hoge et al. concluded that the health complaints were better attributed to PTSD and depression than to TBI. In this study, mild TBI, PTSD, and impaired sleep were strongly associated. Hence, we did not attribute symptoms

\footnotetext{
* Clark ME, Walker RL, Scholten JD, Gironda RJ. Personal communication, 16 February 2008.
} 
solely to PTSD. We feel that TBI and PTSD both contribute to problems that OIF/OEF veterans face in reentering civilian life. In concurrence with Hoge et al. [65], we feel that headaches are better attributed to TBI than to PTSD.

\section{CONCLUSIONS}

We found that OIF/OEF veterans with histories of mild TBI associated with exposure to an explosion in combat could be distinguished based on whether they had residual neurocognitive deficits after the last episode of mild TBI. The blasts were usually caused by improvised explosive devices. Among 126 veterans with histories of mild blast TBI, 80 had residual neurocognitive deficits. Most of the group of 80 had deficits on neurological examination and neuropsychological testing. The veterans with residual neurocognitive deficits had been exposed to more explosions. Veterans who had persisting neurocognitive deficits were more likely to have headaches, PTSD, and impaired sleep. They were more likely to have headaches with migraine features. They had more severe pain and more frequent headaches. While this study cannot establish causality, we propose that links may exist between PTSD, impaired sleep, and headaches. Impaired sleep was highly correlated with the presence of PTSD. Most veterans had impaired sleep due to nightmares, which are a manifestation of PTSD. Disrupted, nonrestorative sleep can worsen neurocognitive impairments and will also intensify headache pain and increase headache frequency.

\section{ACKNOWLEDGMENTS}

This material is the result of work supported by Patient Care Services of the LSCVAMC, Cleveland, Ohio.

The authors have declared that no competing interests exist.

\section{REFERENCES}

1. Ruff R. Two decades of advances in understanding of mild traumatic brain injury. J Head Trauma Rehabil. 2005;20(1): 5-18. [PMID: 15668567]
2. Taber KH, Warden DL, Hurley RA. Blast-related traumatic brain injury: What is known? J Neuropsychiatry Clin Neurosci. 2006;18(2):141-45. [PMID: 16720789]

3. Warden D. Military TBI during the Iraq and Afghanistan wars. J Head Trauma Rehabil. 2006;21(5):398-402. [PMID: 16983225]

4. Headache Classification Subcommittee of the International Headache Society. The International Classification of Headache Disorders: 2nd ed. Cephalalgia. 2004;24 Suppl 1:9-160. [PMID: 14979299]

5. Linder SL. Post-traumatic headache. Curr Pain Headache Rep. 2007;11(5):396-400. [PMID: 17894931]

6. Walker WC, Seel RT, Curtiss G, Warden DL. Headache after moderate and severe traumatic brain injury: A longitudinal analysis. Arch Phys Med Rehabil. 2005;86(9): 1793-1800. [PMID: 16181945]

7. Lew HL, Lin PH, Fuh JL, Wang SJ, Clark DC, Walker WC. Characteristics and treatment of headache after traumatic brain injury: A focused review. Am J Phys Med Rehabil. 2006;85(7):619-27. [PMID: 16788394]

8. Schwab KA, Ivins B, Cramer G, Johnson W, Sluss-Tiller M, Kiley K, Lux W, Warden D. Screening for traumatic brain injury in troops returning from deployment in Afghanistan and Iraq: Initial investigation of the usefulness of a short screening tool for traumatic brain injury. J Head Trauma Rehabil. 2007;22(6):377-89. [PMID: 18025970]

9. Malec JF, Brown AW, Leibson CL, Flaada JT, Mandrekar JN, Diehl NN, Perkins PK. The Mayo classification system for traumatic brain injury severity. J Neurotrauma. 2007; 24(9):1417-24. [PMID: 17892404]

10. Esselman PC, Uomoto JM. Classification of the spectrum of mild traumatic brain injury. Brain Inj. 1995;9(4):417-24. [PMID: 7640688]

11. Kay T, Harrington DE, Adams R, Anderson T, Berrol S, Cicerone K, Dahlberg C, Gerber D, Goka R, Harley P, Hilt J, Horn L, Lehmkuhl D, Malec J. Definition of mild traumatic brain injury. J Head Trauma Rehabil. 1993;8:86-87.

12. Kushner D. Mild traumatic brain injury: Toward understanding manifestations and treatment. Arch Intern Med. 1998;158(15):1617-24. [PMID: 9701095]

13. Samuels MA, Feske SK. Office practice of neurology. 2nd ed. New York (NY): Churchill Livingston; 2003. p. 1661.

14. Nasreddine ZS, Phillips NA, Bédirian V, Charbonneau S, Whitehead V, Collin I, Cummings JL, Chertkow H. The Montreal Cognitive Assessment, MoCA: A brief screening tool for mild cognitive impairment. J Am Geriatr Soc. 2005; 53(4):695-99. [PMID: 15817019]

15. Zadikoff C, Fox SH, Tang-Wai DF, Thomsen T, de Bie RM, Wadia P, Miyasaki J, Duff-Canning S, Lang AE, Marras C. A comparison of the Mini Mental State Exam to the Montreal cognitive assessment in identifying cognitive deficits in 
Parkinson's disease. Mov Disord. 2007;23(2):297-99. [PMID: 18044697]

16. Doty RL, Marcus A, Lee WW. Development of the 12-item Cross-Cultural Smell Identification Test (CC-SIT). Laryngoscope. 1996;106(3 Pt 1):353-56. [PMID: 8614203]

17. Doty RL. Olfaction. Annu Rev Psychol. 2001;52:423-52. [PMID: 11148312]

18. Doty RL, Frye RE, Agrawal U. Internal consistency reliability of the fractionated and whole University of Pennsylvania Smell Identification Test. Percept Psychophys. 1989; 45(5):381-84. [PMID: 2726398]

19. De Kruijk JR, Leffers P, Menheere PP, Meerhoff S, Rutten J, Twijnstra A. Olfactory function after mild traumatic brain injury. Brain Inj. 2003;17(1):73-78. [PMID: 12519649]

20. Doty RL, Yousem DM, Pham LT, Kreshak AA, Geckle R, Lee WW. Olfactory dysfunction in patients with head trauma. Arch Neurol. 1997;54(9):1131-40. [PMID: 9311357]

21. Levin HS, High WM, Eisenberg HM. Impairment of olfactory recognition after closed head injury. Brain. 1985; 108(Pt 3):579-91. [PMID: 4041775$]$

22. Callahan CD, Hinkebein JH. Assessment of anosmia after traumatic brain injury: Performance characteristics of the University of Pennsylvania Smell Identification Test. J Head Trauma Rehabil. 2002;17(3):251-56. [PMID: 12086578]

23. London B, Nabet B, Fisher AR, White B, Sammel MD, Doty RL. Predictors of prognosis in patients with olfactory disturbance. Ann Neurol. 2008;63(2):159-66. [PMID: 18058814]

24. Sawyer RN Jr, Hanna JP, Ruff RL, Leigh RJ. Asymmetry of forearm rolling as a sign of unilateral cerebral dysfunction. Neurology. 1993;43(8):1596-98. [PMID: 8351018]

25. Khasnis A, Gokula RM. Romberg's test. J Postgrad Med. 2003;49(2):169-72. [PMID: 12867698]

26. Kremer E, Atkinson JH, Ignelzi RJ. Measurement of pain: Patient preference does not confound pain measurement. Pain. 1981;10(2):241-48. [PMID: 7267140$]$

27. Graham JR. MMPI-2: Assessing personality and psychopathology. 3rd ed. New York (NY): Oxford University Press; 1999. p. 256.

28. Johnstone B, Hexum CL, Ashkanazi G. Extent of cognitive decline in traumatic brain injury based on estimates of premorbid intelligence. Brain Inj. 1995;9(4):377-84. [PMID: 7640683]

29. Ryan JJ, Schnakenberg-Ott SD. Scoring reliability on the Wechsler Adult Intelligence Scale-Third Edition (WAISIII). Assessment. 2003;10(2):151-59. [PMID: 12801187]

30. Suchy Y, Leahy B, Sweet JJ, Lam CS. Behavioral Dyscontrol Scale deficits among traumatic brain injury patients, part II: Comparison to other measures of executive functioning. Clin Neuropsychol. 2003;17(4):492-506.

[PMID: 15168914]

31. Fork M, Bartels C, Ebert AD, Grubich C, Synowitz H, Wallesch CW. Neuropsychological sequelae of diffuse traumatic brain injury. Brain Inj. 2005;19(2):101-8. [PMID: 15841754]

32. Gronwall DM. Paced auditory serial-addition task: A measure of recovery from concussion. Percept Mot Skills. 1977; 44(2):367-73. [PMID: 866038]

33. Tombaugh TN, Stormer P, Rees L, Irving S, Francis M. The effects of mild and severe traumatic brain injury on the auditory and visual versions of the Adjusting-Paced Serial Addition Test (Adjusting-PSAT). Arch Clin Neuropsychol. 2006; 21(7):753-61. [PMID: 17071365]

34. Ozakbas S, Ormeci B, Akdede BB, Alptekin K, Idiman E. Utilization of the auditory consonant trigram test to screen for cognitive impairment in patients with multiple sclerosis: Comparison with the paced auditory serial addition test. Mult Scler. 2004;10(6):686-89. [PMID: 15584495]

35. Brooks J, Fos LA, Greve KW, Hammond JS. Assessment of executive function in patients with mild traumatic brain injury. J Trauma. 1999;46(1):159-63. [PMID: 9932700]

36. Demakis GJ. Frontal lobe damage and tests of executive processing: A meta-analysis of the Category Test, Stroop Test, and Trail-Making Test. J Clin Exp Neuropsychol. 2004; 26(3):441-50. [PMID: 15512932]

37. Western SL, Long CJ. Relationships among neuropsychological test performance, history of traumatic brain injury, and level of distress. Arch Clin Neuropsychol. 1997;12(4): 426-27.

38. Lipsky RH, Sparling MB, Ryan LM, Xu K, Salazar AM, Goldman D, Warden DL. Association of COMT Val158Met genotype with executive functioning following traumatic brain injury. J Neuropsychiatry Clin Neurosci. 2005;17(4): 465-71. [PMID: 16387984]

39. Maujean A, Shum D, McQueen R. Effect of cognitive demand on prospective memory in individuals with traumatic brain injury. Brain Impair. 2003;4(2):135-45.

40. Iverson GL, Franzen MD, Lovell MR. Normative comparisons for the controlled oral word association test following acute traumatic brain injury. Clin Neuropsychol. 1999; 13(4):437-41. [PMID: 10806456$]$

41. Kerr C. Dysnomia following traumatic brain injury: An information-processing approach to assessment. Brain Inj. 1995;9(8):777-96. [PMID: 8605511]

42. McDonald BC, Flashman LA, Saykin AJ. Executive dysfunction following traumatic brain injury: Neural substrates and treatment strategies. NeuroRehabilitation. 2002; 17(4):333-44. [PMID: 12547981$]$

43. Bennett PC, Ong B, Ponsford J. Assessment of executive dysfunction following traumatic brain injury: Comparison of the BADS with other clinical neuropsychological measures. J Int Neuropsychol Soc. 2005;11(5):606-13. [PMID: 16212688]

44. Bowden SC, Fowler KS, Bell RC, Whelan G, Clifford CC, Ritter AJ, Long CM. The reliability and internal validity of 
the Wisconsin Card Sorting Test. Neuropsychol Rehabil. 1999;8(3):243-54.

45. Benge JF, Caroselli JS, Temple RO. Wisconsin Card Sorting Test: Factor structure and relationship to productivity and supervision needs following severe traumatic brain injury. Brain Inj. 2007;21(4):395-400. [PMID: 17487637]

46. Serra-Grabulosa JM, Junqué C, Verger K, Salgado-Pineda P, Mañeru C, Mercader JM. Cerebral correlates of declarative memory dysfunctions in early traumatic brain injury. J Neurol Neurosurg Psychiatry. 2005;76(1):129-31. [PMID: 15608014]

47. Wilde MC, Castriotta RJ, Lai JM, Atanasov S, Masel BE, Kuna ST. Cognitive impairment in patients with traumatic brain injury and obstructive sleep apnea. Arch Phys Med Rehabil. 2007;88(10):1284-88. [PMID: 17908570]

48. Meyers JE, Bayless JD, Meyers KR. Rey complex figure: Memory error patterns and functional abilities. Appl Neuropsychol. 1996;3(2):89-92. [PMID: 16318537]

49. Lichtenberger EO, Kaufman AS, Lai ZC. Essentials of WMS-III assessment. New York (NY): John Wiley and Sons; 2001. p. 288.

50. Fisher DC, Ledbetter MF, Cohen NJ, Marmor D, Tulsky DS. WAIS-III and WMS-III profiles of mildly to severely braininjured patients. Appl Neuropsychol. 2000;7(3):126-32. [PMID: 11125705]

51. McAllister TW, Flashman LA, McDonald BC, Saykin AJ. Mechanisms of working memory dysfunction after mild and moderate TBI: Evidence from functional MRI and neurogenetics. J Neurotrauma. 2006;23(10):1450-67. [PMID: 17020482]

52. Ord JS, Greve KW, Bianchini KJ. Using the Wechsler Memory Scale-III to detect malingering in mild traumatic brain injury. Clin Neuropsychol. 2007;22(4):689-704. [PMID: 17853130$]$

53. Langeluddecke PM, Lucas SK. Quantitative measures of memory malingering on the Wechsler Memory Scale-Third edition in mild head injury litigants. Arch Clin Neuropsychol. 2003;18(2):181-97. [PMID: 14591470]

54. Donders J. A confirmatory factor analysis of the California Verbal Learning Test-Second Edition (CVLT-II) in the standardization sample. Assessment. 2008;15(2):123-31. [PMID: 18187398]

55. Jacobs ML, Donders J. Performance discrepancies on the California Verbal Learning Test: Second Edition (CVLT-II) after traumatic brain injury. Arch Clin Neuropsychol. 2008; 23(1):113-18. [PMID: 17959354]

56. Suh M, Basu S, Kolster R, Sarkar R, McCandliss B, Ghaja J; Cognitive and Neurobiological Research Consortium. Increased oculomotor deficits during target blanking as an indicator of mild traumatic brain injury. Neurosci Lett. 2006; 410(3):203-7. [PMID: 17055156]
57. Moore BA, Donders J. Predictors of invalid neuropsychological test performance after traumatic brain injury. Brain Inj. 2004;18(10):975-84. [PMID: 15370897]

58. Greve KW, Bianchini KJ, Doane BM. Classification accuracy of the test of memory malingering in traumatic brain injury: Results of a known-groups analysis. J Clin Exp Neuropsychol. 2006;28(7):1176-90. [PMID: 16840243]

59. Greve KW, Bianchini K, Love JM, Brennan A, Heinly MT. Sensitivity and specificity of MMPI-2 validity scales and indicators to malingered neurocognitive dysfunction in traumatic brain injury. Clin Neuropsychol. 2006;20(3): 491-512. [PMID: 16895861]

60. Beck AT, Steer RA, Brown GK. BDI-II: Beck Depression Inventory. 2nd ed. San Antonio (TX): Psychology Corporation; 1996. p. 128.

61. Beck AT, Epstein N, Brown G, Steer RA. An inventory for measuring clinical anxiety: Psychometric properties. J Consult Clin Psychol. 1988;56(6):893-97. [PMID: 3204199]

62. Weathers FW, Huska JA, Keane TM. PCL-M for DSM-IV. Boston (MA): National Center for PTSD_Behavioral Science Division; 1991. Available from: http:// www.oqp.med.va.gov/cpg/PTSD/PTSD_cpg/content/ appendices/appendixC.htm/.

63. Kang HK, Natelson BH, Mahan CM, Lee KY, Murphy FM. Post-traumatic stress disorder and chronic fatigue syndromelike illness among Gulf War veterans: A population-based survey of 30,000 veterans. Am J Epidemiol. 2003;157(2): 141-48. [PMID: 12522021]

64. Hoge CW, Castro CA, Messer SC, McGurk D, Cotting DI, Koffman RL. Combat duty in Iraq and Afghanistan, mental health problems, and barriers to care. N Engl J Med. 2004; 351(1):13-22. [PMID: 15229303]

65. Hoge CW, McGurk D, Thomas JL, Cox AL, Engel CC, Castro CA. Mild traumatic brain injury in U.S. soldiers returning from Iraq. N Engl J Med. 2008;358(5):453-63. [PMID: 18234750]

66. Breslau N, Kessler RC. The stressor criterion in DSM-IV posttraumatic stress disorder: An empirical investigation. Biol Psychiatry. 2001;50(9):699-704. [PMID: 11704077

67. Agresti A. An introduction to categorical data analysis. New York (NY): John Wiley \& Sons; 1996. p. 16-52.

68. Agresti A. An introduction to categorical data analysis. New York (NY): John Wiley \& Sons; 1996. p. 71-102.

69. Van Belle G, Fisher LD, Heagerty PJ, Lumley TS. Chapter 9. Biostatistics: A methodology for the health sciences. New York (NY): John Wiley \& Sons; 2004. p. 345-417.

70. Hochberg Y, Tamhane AC. Multiple comparison procedures. New York (NY): John Wiley \& Sons; 1987.

71. Benjamini Y, Hochberg Y. Controlling the false discovery rate: A practical and powerful approach to multiple testing. J Roy Stat Soc B. 1995;57(1):289-300.

72. Bonne O, Gilboa A, Louzoun Y, Kempf-Sherf O, Katz M, Fishman Y, Ben-Nahum Z, Krausz Y, Bocher M, Lester H, 
Chisin R, Lerer B. Cerebral blood flow in chronic symptomatic mild traumatic brain injury. Psychiatry Res. 2003; 124(3):141-52. [PMID: 14623066]

73. Kraus MF, Susmaras T, Caughlin BP, Walker CJ, Sweeney JA, Little DM. White matter integrity and cognition in chronic traumatic brain injury: A diffusion tensor imaging study. Brain. 2007;130(Pt 10):2508-19. [PMID: 17872928]

74. Busch RM, McBride A, Curtiss G, Vanderploeg RD. The components of executive functioning in traumatic brain injury. J Clin Exp Neuropsychol. 2005;27(8):1022-32. [PMID: 16207623]

75. Doty RL. Office procedures for quantitative assessment of olfactory function. Am J Rhinol. 2007;21(4):460-73. [PMID: 17882917]

76. Kern RC, Quinn B, Rosseau G, Farbman AI. Post-traumatic olfactory dysfunction. Laryngoscope. 2000;110(12):2106-9. [PMID: 11129030]

77. Yousem DM, Geckle RJ, Bilker WB, McKeown DA, Doty RL. Posttraumatic olfactory dysfunction: MR and clinical evaluation. AJNR Am J Neuroradiol. 1996;17(6):1171-79. [PMID: 8791933]

78. Yousem DM, Geckle RJ, Bilker WB, Kroger H, Doty RL. Posttraumatic smell loss: Relationship of psychophysical tests and volumes of the olfactory bulbs and tracts and the temporal lobes. Acad Radiol. 1999;6(5):264-72. [PMID: 10228615]

79. Rinne MB, Pasanen ME, Vartiainen MV, Lehto TM, Sarajuuri JM, Alaranta HT. Motor performance in physically well-recovered men with traumatic brain injury. J Rehabil Med. 2006;38(4):224-29. [PMID: 16801204]
80. Pickett TC, Radfar-Baublitz LS, McDonald SD, Walker WC, Cifu DX. Objectively assessing balance deficits after TBI: Role of computerized posturography. J Rehabil Res Dev. 2007;44(7):983-90. [PMID: 18075955]

81. Kraus MF, Little DM, Donnell AJ, Reilly JL, Simonian N, Sweeney JA. Oculomotor function in chronic traumatic brain injury. Cogn Behav Neurol. 2007;20(3):170-78. [PMID: 17846516]

82. Laurer HL, Bareyre FM, Lee VM, Trojanowski JQ, Longhi L, Hoover R, Saatman KE, Raghupathi R, Hoshino S, Grady MS, McIntosh TK. Mild head injury increasing the brain's vulnerability to a second concussive impact. J Neurosurg. 2001;95(5):859-70. [PMID: 11702878]

83. Longhi L, Saatman KE, Fujimoto S, Raghupathi R, Meaney DF, Davis J, McMillan BSA, Conte V, Laurer HL, Stein S, Stocchetti N, McIntosh TK. Temporal window of vulnerability to repetitive experimental concussive brain injury. Neurosurgery. 2005;56(2):364-74. [PMID: 15670384$]$

84. Sherman KB, Goldberg M, Bell KR. Traumatic brain injury and pain. Phys Med Rehabil Clin N Am. 2006;17(2): 473-90. [PMID: 16616278$]$

85. Clark ME, Bair MJ, Buckenmaier CC 3rd, Gironda RJ, Walker RL. Pain and combat injuries in soldiers returning from Operations Enduring Freedom and Iraqi Freedom: Implications for research and practice. J Rehabil Res Dev. 2007;44(2):179-94. [PMID: 17551872]

Submitted for publication February 22, 2008. Accepted in revised form May 14, 2008. 